\title{
SMART GRID USING RENEWABLE ENERGY, IoT AND HPES SYSTEMS
}

\author{
Shivani Jitendra Khare \\ UG Scholar, \\ Department of Electrical Engineering, \\ Bharati Vidyapeeth Deemed to be University, \\ College of Engineering, Pune, India.
}

\begin{abstract}
Smart grid analysis is the ultimate key for efficient use of available energy sources. This digital technology provides the utility and the customer with a two-way communication. It is an electrical grid that makes use of analog and digital data technology. On the other hand, renewable energy makes it a huge research area. This is because renewable energy is environment friendly and given the applications of renewable energy in smart grid, it makes the grid far more promising. This integration of smart grid with renewable energy makes renewable energy more efficient.
\end{abstract}

At present, the real challenge this review paper seeks is to examine the role of smart grid in energy field. The introductory section of the paper looks into the grid system and various stages involved in the process of generation to distribution. Subsections examines various renewable sources and their availability. Various smart devices and Energy Management systems have been discussed. It also covers the role of IOT technology in smart grid for clean energy. Later the problems of storage and Hydro Pumped Energy Storage (HPES) systems have been explored. Discussions have been made, future recommendations have been given and conclusions from the study have been included.

Keywords: Smart grid, Renewable energy, Smart meters, Energy Management System, IoT, Storage, Hydro Pumped Energy Storage (HPES) systems.

\section{INTRODUCTION}

A convoluted system that is designed to deliver electricity all the way from the generation stage to the distribution stage where the customers receive electricity for their daily use is called an electric grid. An electrical grid usually consists of:

i) Generating unit- These units are generating substations that produce electric power (Wei X., Zhang J., (2016)).

ii) Electric substations- These are the substation that are used from stepping up or down the electric voltage for transmission and distribution purposes respectively.
Swapnil Namekar

Assistant Professor,

Department of Electrical Engineering,

Bharati Vidyapeeth Deemed to be University, College of Engineering, Pune, India.

iii) High voltage transmission lines- These lines serve as a medium for transmission of power from source to demand areas.

iv) Distribution lines-These lines are used to connect to individual customers (Mani V. et al, (2017)).

\section{PROCESS}

This stage can be divided into two subsections-

i) Centralized generation-

This type of generation pertains to large scale generation taking place far off from the consumption (Shahzad U., (2015)). This includes nuclear, coal, hydro, wind and solar arrays. The grid connects the centralized generated power to the customer.

ii) Decentralized generation- This type of generation relates to generation that occurs close to the consumption area (Cheng K.W.E., (2009)). This would include the rooftop solar cell energy management system in houses.

2) Transmission and Distribution-

This component of the grid generally includes transformers, substation and voltage lines that transport electricity from the generation unit to consumption unit. Transmission lines can be overhead or underground. When the power arrives at consumption point, substation steps down the voltage for consumption.

\section{3) Consumption-}

This component of the grid can be divided into the following sections:

i) Industrial consumers

ii) Commercial consumers

iii) Residential consumers.

Each of these components have different electricity demands (Tastan M., (2019)).

There are two types of transmission lines for high voltage transmission. They are- 


\section{International Journal of Engineering Applied Sciences and Technology, 2020 \\ Vol. 4, Issue 12, ISSN No. 2455-2143, Pages 205-210 \\ Published Online April 2020 in IJEAST (http://www.ijeast.com)}

1) High Voltage Alternating Current line (HVAC line)-

In this type of interconnection, the two AC networks are connected by an AC link (Prasad I., (2014)). For the interconnection to take place, frequency control on each of the two networks is requisite. The frequency for a 50 hertz system should lie between 48.5 and 51.5. This interconnection is known as synchronous interconnection.

Limitations:

i) Frequency disturbances occurring in one system gets transmitted to other (Hiwale A.P. et al, (2018)).

ii) Power variations in one system affect the other system leading to entire failure of the interconnected network.

2) High Voltage Direct Current line (HVDC line)-

This type of interconnection of networks consist of a loose coupling between two interconnected AC network. DC connection is also called as DC tie. This DC tie is non synchronous.

Benefits:

i) The system which is to be connected requires to be at same frequency being asynchronous. As a result of which it also permits the network to operate independently and maintain the standards of frequency.

ii) HVDC link delivers fast control of magnitude and direction of flow of power by controlling firing angles (Marinakis V. et al, (2018)). This control enables increase in the limit of transient stability.

Applications of HVDC lines include transmission of renewable energy over long distances with minimal losses and hence delivered to the grid.

\section{SMART GRID AND COMPONENTS}

A smart grid is an electrical grid which by the application of digital technology computers, control and automation equipment's allow for two-way communication between the utility and consumer. The block diagram is shown in Fig-1.

\section{BLOCK DIAGRAM- Components of Smart Grid}

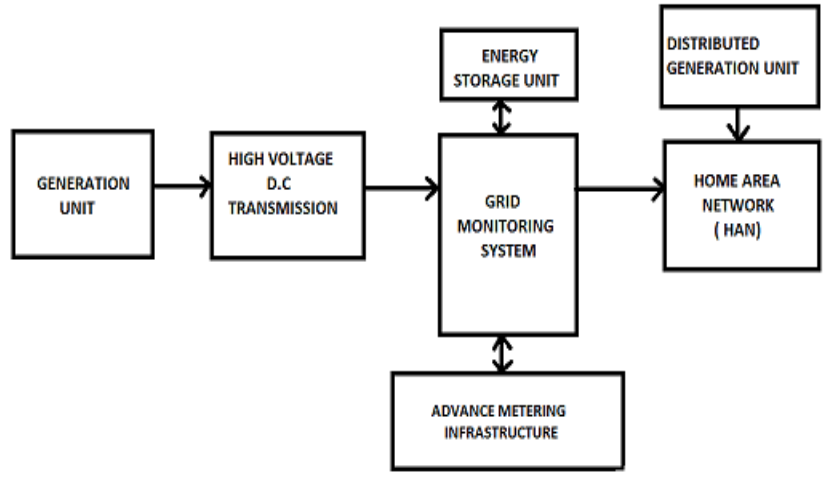

Fig-1: Block Diagram of Smart Grid

\section{RENEWABLE ENERGY}

The form of energy that is replenishing naturally in the environment is known as Renewable energy. This source of energy is inexhaustible virtually provided they are limited in quantity of energy available per unit time.

Renewable energy is being useful in substituting "dirty fossil fuels" in power section which in turn results in lower carbon emissions and other pollutants. Expansion of renewable energy is taking place at scales both large and small such as solar panels on rooftop in houses which is capable of selling electric power back to the grid to offshore wind farms. There exist entire rural communities which use renewable energy for lighting and heating purposes.

As renewable energy applications are widespread and are growing progressively with time, the key aim is to modernize the existing electricity grid advancing it into a smarter, better, integrated and more secure system across the nation.

\section{TYPES OF RENEWABLE ENERGY}

i) Solar Energy- Solar also called photovoltaic cells are manufactured from silicon or materials that capture sunlight and transform it directly into electricity. Solar farms are capable of generating power for thousands of homes by application of mirrors in order to concentrate sunlight on solar cells.

ii) Wind Energy- Wind is usually the outcome of uneven heating of surface of earth by sun. Earth absorbs heat at various rates due to land and water conditions. Wind farms capture energy of flowing wind by the application of turbine. This energy gets converted into electricity.

iii) Hydro Energy- This form of renewable energy is the largest source (Wei X. et al, (2016)). Hydro means water which technically refers to fast moving water in river or falling from a height. Force of falling water is taken into application and converts water to electricity by revolution of turbine blades of generator.

iv) Geothermal Energy- Geothermal heat is a type a renewable energy that is trapped below the crust of Earth. At times this internal heat escapes all at once leading to occurrences such as geysers and volcanic eruptions. This heat can be taken into account to produce geothermal energy by application of steam as a outcome from heated water pumped below surface which then rises to the top and is applied in operation of turbine.

\section{RENEWABLE ENERGY IN SMART GRID}

In global energy mix world, in order to achieve double of renewable energy share, increasing the amount of renewable electricity generation is the key component (Shahzad U., (2015)). Such a system is feasible 


\section{International Journal of Engineering Applied Sciences and Technology, 2020 \\ Vol. 4, Issue 12, ISSN No. 2455-2143, Pages 205-210 \\ Published Online April 2020 in IJEAST (http://www.ijeast.com)}

technically but will require certain upgrades to the old grid systems in practice and operationalizing modern solutions in order to accommodate renewable energy generation of varied types. The upgrade to old grids is smart grids. Smart grids are capable of incorporating the following characteristics:

i) Variability- Certain forms of renewable electricity generation such as solar and wind are dependent on fluctuating resource for their outcomes. Ideally, electricity supply must be available at all times. Hence efforts are needed in order to ensure electricity sources are available that are able to eliminate variability.

ii) Distributed generation- Small scale systems which are privately owned and operated are distributed renewable energy generation system (Prasad I., (2014)). Old utilities are not able to allow such systems to connect to the grid due to safety concerns, grid stabilities and operational difficulties in valuing and pricing generation.

iii) Quicker restoration after power disturbances.

iv) Reduce operation and management cost.

v) Reduce peak demand and hence lower the rates.

vi) Add resiliency to power system and prepares for emergencies such as storms, earthquakes.

vii) Takes advantage of customer owned power generation when not available from utilities.

As per Wikipedia, Fig-2 represents the installed grid renewable power capacity.

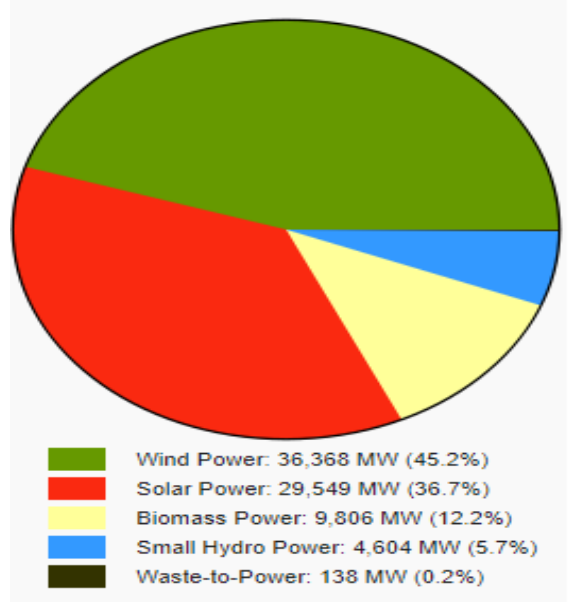

Fig-2: Installed grid renewable power capacity.

\section{Customer benefits-}

i) Gives information and tools to make choices about energy use.

ii) Unprecedented level of customer participation.

iii) Customers no longer have to wait for monthly statement to know energy usage.

\section{SMART METERS}

Smart meters are meters provide smart grid interface between energy provider and the user. These meters operate digitally and allow complex and automated transfers of data between customer and provider. They deliver signals from energy provider that can cut the cost of energy. This whole process of communication of information between provider and customer can take place by a home energy management system (EMS). This system tracks the use of energy in detail to save energy.

\section{ENERGY MANAGEMENT SYSTEM}

Energy management system is a system that tracks energy usage to limit the wastage of energy. This system can be made more efficient by integration of renewable energy with energy management system. Since renewable energy is ecofriendly, easily available and is bound to satisfy the needs of the generation, usage of this system is an added advantage. This system creates settings to automatically use power at lowest prices. This system is easily viewable on a computer or a handset. The customer can choose specific settings that can allow specific machines to turn down when the demand in the system increases.

Distribution intelligence- This is a subpart of smart grid systems which is responsible for making smart grid more efficient and technology friendly. It applies to utility distribution system that include switches, cables and wires. There are many utilities that depend on consumer calls to detect which specific areas are being strained by power outage. Distribution intelligence system along with Smart meters enable the utility to pin point the source of power outrage in order to repair the affected area by the repair crews. This is how distribution intelligence is of great use.

\section{IOT TECHNOLOGY FOR SMART GRID}

IOT has comprehensive sensing and processing capabilities. Smart grid is reliable in processing, disaster management and warning mechanisms (Mani V., et al, (2017)). It is a self-healing grid. By self-healing it is meant that the grid can handle transmission control phenomenon.

This characteristic is capable of avoiding unproductive flows of current that leads to energy wastage. Software mechanisms can monitor the smart grid in real time for disturbances that is the main cause of power cuts (blackouts) (Marinakis V. et al, (2018)). This could dampen the disturbance oscillations in the grid route power through the smart grid. In cases when current needs to be removed from reaching the consumer, control software designed can route the power in order to experience minimal disruptions. The block diagram is shown in Fig-3. 
X. BLOCK DIAGRAM

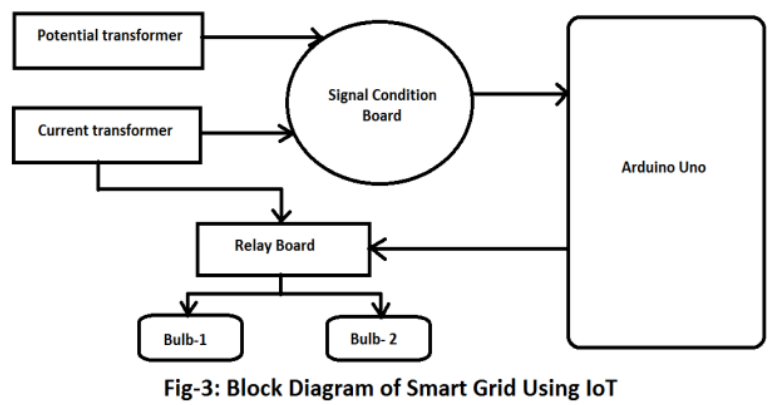

Smart grid can be controlled by IoT technology due to following reasons:

i) IoT can monitor generation of power plants and check upon the gas emissions taking place in the plant. It can also maintain a record of energy storage.

ii) IoT can achieve electricity consumption, monitor transmission lines, towers, substations and equipment's.

iii) AMI with increased reliability- AMI is automatic metering infrastructure. This also forms the main component in operation of smart grid. IoT technology can be used to detect abnormality in smart grid, collect data from various sources and exchange information between smart meters in order to check amount of distributed energy, quality of energy and pattern in which consumption of power is taking place by the consumers.

iv) SMART HOME- This mechanism can be used for interaction purposes to occur between users and smart grid (Tastan M., (2019)). This can also use to enhance smart grid services, improve QoS, meet market demand, monitor renewable energy and read consumption power which is gathered by smart meters.

v) Transmission line monitoring- Broadband connections can be used to monitor, discover and eliminate the areas with faulty issues.

vi) ELECTRICAL VEHICLES assistant management system: This system comprises of charging station, monitoring system of the electrical vehicle (Hiwale A.P., et al (2018)). By the application of GPS, the customers can keep the track of nearby charging stations and availability of parking (Cheng K.W.E., (2009)). GPS technology would automatically guide the customers to most suitable charging station available in the neighborhood. The monitoring center is capable of managing charging equipment's, batteries of car and charging stations.

\section{PROBLEM IN SMART GRID}

As said every coin has two sides. The one side can have many advantages while the other side can have disadvantages too. The same applies to renewable energy. When we take the application of renewable energy in consideration, these sources provide their respective energy in their respective energy in their presence only. Renewable resources such as solar and wind are usable only when wind is blowing or the sun is shining (Golande S., et al, (2018)). As a result of this scenario:

i) The production of power does not match the particular peak demand time. The renewable energy offers either not enough capacity when in need or too much energy when not needed at any time.

ii) Now-a-days the demand is quite unpredictable. Earlier, the demand was stable and predictable. But as the cost of energy and environmental concerns began to rise simultaneously, consumers started changing their behavior of energy usage and this resulted in high fluctuations in the demand of the consumers. As a consequence, maintenance of reliability and avoiding outages in the electricity system is becoming more difficult (Tao Ma, et al (2014))

Hence there is a need of an energy storage system that would serve the purpose of storing energy when the produce due to wind and sun is excess and when the demand is low. This system would enable the grid to survive high load demands and avoid waste of the produced energy. This would make the energy management for the smart grid efficient. The energy storage system proposed in this paper is Hydro Pump Energy Storage Systems.

\section{HYDRO PUMPED ENERGY STORAGE SYSTEMS}

Hydro Pumped Energy Storage Systems (HPES) are energy storage systems which work on the phenomenon of storing energy in the form of hydro (water) in a reservoir place at a certain height known as an upper reservoir. This upper reservoir is pumped from a secondary reservoir which is located at a lower elevation called the lower reservoir. These storage systems consist of the following components:

i) Upper Reservoir- In the times of shortage of electric power when supply is necessary from storage systems, water stored containing energy in the upper reservoir is fed into the underground tunnel.

ii) Intake Tunnel- The water which is fed rushes down the intake tunnel.

iii) Turbines- The turbines are located at the base of the dam. These turbines are underground (Tao $\mathrm{Ma}$, et al (2014)). These turbines are driven by the 


\section{International Journal of Engineering Applied Sciences and Technology, 2020 \\ Vol. 4, Issue 12, ISSN No. 2455-2143, Pages 205-210 \\ Published Online April 2020 in IJEAST (http://www.ijeast.com)}

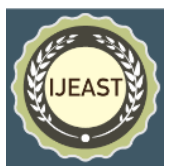

force of water which is fed by upper reservoir through the intake tunnel. The rotation/spinning of the turbine occurs. These turbines are connected to large generators which produce electricity.

iv) Discharge Tunnel- The water then flows into the discharge tunnel to the lower reservoir.

v) Lower Reservoir- The water from the discharge tunnel gets collected here.

vi) Recharging- When the demand for electric energy is low and stabilized, the turbines make a backward spin and as a result of this spin, the water is fed back into the upper reservoir. This action of backward spin makes the water usable and available for generation of electric energy.

The mechanisms however consist of an open loop systems and closed loop systems. During intervals of high demand, the electric power is generated by releasing the stored water (S. Rehman, et al (2015)). During the periods of low demand, the upper reservoir gets recharged by decreasing the amount of electricity from grid to pump the water back to the upper reservoir.

The HPES system equips balancing, stability, provision of storage capacities and network frequency control services (W.P. Schill, et al, (2011)). The abovementioned applications are possible only due to the characteristic ability of pumped storage systems to respond to large electricity load changes within seconds of time. By increasing the capacity in reference of size and number of units, HPES system generation can be varied and shaped in order to match the intervals of high demands.

\section{CONCLUSION}

In this paper we discussed Smart grid as an improved network for generation and distribution purposes. We also emphasized on renewable energy in smart grid and studied smart systems and appliances. We discussed Internet of Things as a network of networks and investigated its developments and IoT infrastructure used in Smart grid.

\section{PROSPECTS}

The future of Smart grid will include improved usage of available resources with minimal amount of wastage. The current problem of the grid includes accommodating variable power resources like wind energy, solar energy, hydro energy and thermal energy (Shakerighadi B. et al (2018)). As these sources continue to supply higher power to the grid, integrating these sources together is quite a difficult task to be worked on. This is because wind, solar, hydro, geothermal sources are located in remote areas where power demand is not high. The power demands increase as one moves from remote to urban areas. Thus, integrating these sources is difficult. The solution to this problem is having increased storage capacity in order to absorb excess amounts of wind, solar and

geothermal energies when they are not in use and release this stored capacity when wind energy and solar energy dips. Also, grid operators require new tools in order to reduce power demand quickly in order to avoid wastage of energy. Therefore, Smart grid technology is capable of performing this task with more advancement for improved results

\section{ACKNOWLEDGEMENT}

We would like to express our special thanks of gratitude to Dr. D.S. Bankar, Head, Department of Electrical Engineering for their guidance and support for completing my review paper. I would also like to thank the faculty members of the department of electrical engineering who helped us with extended support.

\section{REFERENCE}

[1] Wei X., Zhang J., (2016). "Research on renewable energy power generation complementarity and storage distribution model". International Conference on Energy Engineering and Environmental Protection, doi:10.1088/1755-1315/52/1/012042.

[2] Shahzad U., (2015)." The Need for Renewable Energy Sources". International Journal of Information Technology and Electrical Engineering, ISSN:2306$708 \mathrm{X}$.

[3] Mani V., Abhilasha, Gunasekhar, (2017). "IoT Based Smart Energy Management System". International Journal of Applied Engineering Research. Vol 12, ISSN 0973-4562.

[4] Marinakis V., Doukas H., (2018). “An Advanced IoT-based System for Intelligent Energy Management in Buildings”. Sensors, doi:10.3390/s18020610.

[5] Cheng K.W.E., (2009). "Recent Development on Electric Vehicles". International Conference on Power Electronics Systems and Applications, Digital Reference: K210509001.

[6] Shakerighadi B., Moghaddam A.A., Vasquez J.C., Guerrero J.M., (2018). "Internet of Things for Modern Energy Systems: State-of-the-Art, Challenges, and Open Issues". Energies, doi:10.3390/en 11051252.

[7] Tastan M., (2019). "Internet of Things based Smart Energy Management for Smart Home". KSII Transactions on Internet and Information Systems, Vol. 13, ISSN: 1976-7277.

[8] Prasad I., (2014). "Smart Grid Technology: Application and Control". International Journal of Advanced Research in Electrical, Electronics and Instrumentation Engineering. Vol. 3 Issue 5, ISSN (Print): $2320-3765$. 
[9] Hiwale A.P., Gaikwad D.S, Dongare A.A., Mhatre P.C. (2018). "IoT based Smart Energy monitoring". International Research Journal of Engineering and Technology (IRJET). Vol 5, Issue 3, e-ISSN: 2395-0056.

[10] Golande S., Kalgunde M. (2018). "Energy storage using pumped hydro storage based on standalone photovoltaic power generation system". IEEE Xplore. DOI: 10.1109/ICPCSI.2017.8392262.

[11] Tao Ma, Yang H., Lin Lu, "Feasibility study and economic analysis of pumped hydro storage and battery storage for a renewable energy powered island", 2014 ELSEVIER Energy Conversion and Management, Vol. 79, pp. 387-397, 2014.
[12] Tao Ma, Hongxing Yang, Jinqing Peng, "Technical feasibility study on a standalone hybrid solar-wind system with pumped hydro storage for a remote island in Hong Kong", 2014 ELSEVIER Renewable Energy, Vol. 69, pp. 7-15, 2014.

[13] S. Rehman, L.M. Al-Hadhrami, M.M. Alam (2015), "Pumped hydro energy storage system: a technological review". Renew Sustain Energy Rev, pp. 586-598.

[14] W.P. Schill, C. Kemfert (2011), “Modeling strategic electricity storage: the case of pumped hydro storage in Germany Energy J", pp. 59-87. 